\title{
Corrosion products and mechanism on NiTi shape memory alloy in physiological environment
}

\author{
$\mathrm{TaO} \mathrm{Hu}$ \\ Department of Physics \& Materials Science, City University of Hong Kong, \\ Kowloon, Hong Kong \\ Chenglin $\mathrm{Chu}^{\mathrm{a})}$ \\ Department of Physics \& Materials Science, City University of Hong Kong, Kowloon, \\ Hong Kong; and School of Materials Science and Engineering, and Jiangsu Key Laboratory for \\ Advanced Metallic Materials, Southeast University, Nanjing 211189, China \\ Yunchang Xin \\ Department of Physics \& Materials Science, City University of Hong Kong, Kowloon, \\ Hong Kong; and School of Materials Science and Engineering, Chongqing University, \\ Chongqing 400044, China \\ Shuilin $\mathrm{Wu}$ \\ Department of Physics \& Materials Science, City University of Hong Kong, Kowloon, \\ Hong Kong; and China Ministry of Education, Key Laboratory for the Green Preparation \\ and Application of Functional Materials, School of Materials Science and Engineering, \\ Hubei University, Wuhan 430062, China \\ Kelvin W.K. Yeung \\ Department of Physics \& Materials Science, City University of Hong Kong, \\ Kowloon, Hong Kong; and Department of Orthopaedics \& Traumatology, \\ The University of Hong Kong, Hong Kong \\ Paul K. Chu ${ }^{\text {b) }}$ \\ Department of Physics \& Materials Science, City University of Hong Kong, \\ Kowloon, Hong Kong
}

(Received 31 August 2009; accepted 3 October 2009)

Despite many investigations on the corrosion behavior of NiTi shape memory alloys (SMAs) in various simulated physiological solutions by electrochemical measurements, few have reported detailed information on the corrosion products. In the present study, the structure and composition of the corrosion products on NiTi SMAs immersed in a $0.9 \% \mathrm{NaCl}$ physiological solution are systematically investigated by scanning electron microscopy (SEM), x-ray energy dispersion spectroscopy (EDS), and x-ray photoelectron spectroscopy (XPS). It is found that attack by $\mathrm{Cl}^{-}$results in nickel being released into the solution and decrease in the local nickel concentration at the pitting sites. The remaining Ti reacts with dissolved oxygen from the solution to form titanium oxides. After longterm immersion, the corrosion product layer expands over the entire surface and XPS reveals that the layer is composed of $\mathrm{TiO}_{2}, \mathrm{Ti}_{2} \mathrm{O}_{3}$, and $\mathrm{TiO}$ with relatively depleted $\mathrm{Ni}$. The growth rate of the corrosion product layer decreases with immersion time, and the corrosion product layer is believed to impede further corrosion and improve the biocompatibility of NiTi alloy in a physiological environment. It is found that the release rate of nickel is related to the surface structure of the corrosion product layer and immersion time. A corrosion mechanism is proposed to explain the observed results.

\section{INTRODUCTION}

NiTi SMAs as biomaterials are used in medical implants and devices such as orthodontic wires, self-

Address all correspondence to these authors.

a)e-mail: clchu@seu.edu.cn

b)e-mail: paul.chu@cityu.edu.hk

DOI: $10.1557 / J M R .2010 .0051$ expanding cardiovascular and urological stents, spine correction rods, bone fraction fixation plate and staples, and so on. ${ }^{1-5}$ The reasons for adopting NiTi SMAs in biomedical implants are their unique shape memory effects and superelasticity properties, low Young's modulus compared with stainless steels and titanium alloys, reliable and stable mechanical properties, as well as good biocompatibility. ${ }^{6-8}$ However, as are other metallic implants, when 
NiTi SMAs are subjected to the physiological environment, the corrosion behavior affects not only their biocompatibility but also long-term implantation safety in the human body. It has been reported that corrosion causes outdiffusion of harmful nickel ions that may induce hypersensitive reactions and tissue necrosis. ${ }^{9,10}$ Because the human body constitutes an aggressive corrosion environment, the presence of ionic salts in body fluids can corrode NiTi alloys and further accelerate Ni outdiffusion from the substrate. Up to now, although many studies have been carried out to investigate the corrosion behavior of biomedical NiTi alloys under different physiological environments in vitro, most of them have focused on $\mathrm{Ni}$ release from the bulk materials to the physiological solution and electrochemical properties such as the open circuit potential, dynamic polarization as well as electrochemical impedance spectroscopy (EIS), which have been considered to be closely linked to biocompatibility. ${ }^{11-19}$ After the NiTi alloys are implanted into human body, they will be attacked by aggressive ions in the body fluids such as chlorides, hydrocarbonates, and sulfates that further corrode the NiTi implants and form corrosion products on the surface. The nature of this corrosion product layer not only influences the subsequent corrosion process of the substrate, ${ }^{8}$ but may also affect the biological behavior of bone tissues. However, the structure of the corrosion product layer, exact constituents and their distribution, and formation mechanisms are still not clear and well understood. The main reason is that the corrosion rate of NiTi SMAs in a physiological solution is low compared with other biomedical metals such as magnesium alloys. ${ }^{20}$ Therefore, it is crucial to indentify the constituents and mechanism of the corrosion product layer on NiTi SMAs to enable more trouble-free clinical use of the materials.

Because human body fluids contain a high concentration of $\mathrm{Cl}^{-}$that can cause pitting corrosion on the surface of implants ${ }^{21}$ the present work aims at investigating the corrosion products and mechanism on NiTi SMAs in an aggressive chloride ion environment. In the work described here, immersion tests are conducted in $0.9 \%$ $\mathrm{NaCl}$ physiological solution. The morphology and composition of the NiTi surface are investigated by scanning electron microscopy (SEM), x-ray energy dispersion spectroscopy (EDS), and x-ray photoelectron spectroscopy (XPS). The amounts of nickel ions released from the NiTi specimens were measured by inductively coupled plasma atomic emission spectrometer (ICPAES). The corresponding corrosion mechanism of the NiTi SMAs in $0.9 \% \mathrm{NaCl}$ physiological solution is proposed.

\section{EXPERIMENTAL DETAILS}

The materials used were commercial superelastic NiTi bar (SE508, Nitinol Device \& Components, Fremont, CA) consisting of 50.8 at.\% $\mathrm{Ni}$ and 49.2 at.\% Ti. The raw materials were cut into $1 \mathrm{~mm}$ thick and $4.8 \mathrm{~mm}$ diameter disks. The specimens were polished by $\mathrm{SiC}$ sandpaper to grade 1200 followed by ultrasonic cleaning in acetone and deionized water for $10 \mathrm{~min}$. The cleaned specimens were immersed in $80 \mathrm{~mL}$ of $0.9 \% \mathrm{NaCl}$ physiological solution in a polypropylene (PP) bottle. The polypropylene bottles were closed tightly and incubated in a thermostatic chamber at $37 \pm 0.5^{\circ} \mathrm{C}$ for $2,5,8,12$, and 30 weeks, respectively. Each PP bottle contained one NiTi specimen, and there were three parallel PP bottles for each time point. After different immersion times, the solutions were analyzed by ICPAES to determine the amounts of Ni leached from the specimens.

The surface morphologies on the NiTi specimens were observed using SEM. The surface composition and depth profiles in the near-surface region of the NiTi samples were determined by XPS (Physical Electronics PHI 5802, Chanhassen, $\mathrm{MN}$ ) with monochromatic $\mathrm{Al} \mathrm{K} \alpha \mathrm{x}$-ray radiation $(1486.6 \mathrm{eV})$. High-resolution Ti 2p, O 1s, and Ni 2p spectra were acquired at $20 \mathrm{eV}$ pass energy to determine the chemical states and concentrations. The $\mathrm{C} 1 \mathrm{~s}$ peak was used to identify any charging effects. The XPS depth profiles were obtained using a rastered $3 \mathrm{keV} \mathrm{Ar}+$ ion beam. The oxide thickness was estimated by taking the depth when the O signal dropped to $50 \%$ of the maximum value. The sputtering rate of the oxide film was estimated to be $7.8 \mathrm{~nm} / \mathrm{min}$ based on an average sputtering rate calculated from a $\mathrm{SiO}_{2}$ reference under similar conditions. ${ }^{22}$

\section{RESULTS AND DISCUSSION}

Figure 1 shows the SEM images acquired from the NiTi specimens immersed for 2, 5, and 8 weeks. As shown in Fig. 1(a), some dark spots observed on the surface of the NiTi specimen after immersion for 2 weeks can be identified as initial pitting corrosion in the $\mathrm{NaCl}$ solution. Figure 1(b) depicts more serious pitting corrosion after immersion for 5 weeks. With attack by $\mathrm{Cl}^{-}$from the $\mathrm{NaCl}$ solution, the dark spots transform into tiny pores on the surface. When the immersion time is increased to 8 weeks, some of the pores propagate into the large corrosion spots as indicated by arrows in Fig. 1(c). The high-magnification image shows that these corrosion spots feature a hole in the center surrounded by several gray spots indicated by white arrows in Fig. 1(d). These newly formed gray spots indicate that after immersion for 8 weeks, new pitting sites still occur on the surface of NiTi specimens. According to the color variation observed from the corrosion spots, it can be concluded that the darker the corrosion spot, the more severe is corrosion. Pitting corrosion causes dissolution of the bulk materials into the corrosive environment, consequently forming pores on the NiTi SMAs.

To determine the elemental compositions in the corroded layer, four representative regions 1 to 4 in Fig. 1(d) 


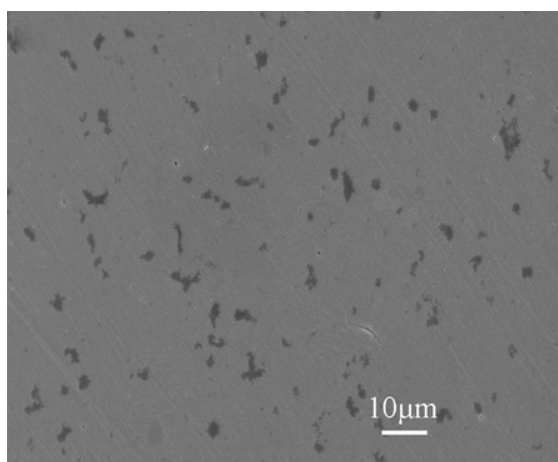

(a)

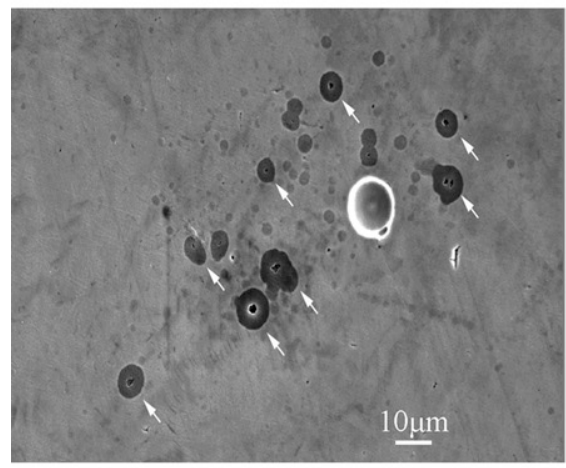

(c)
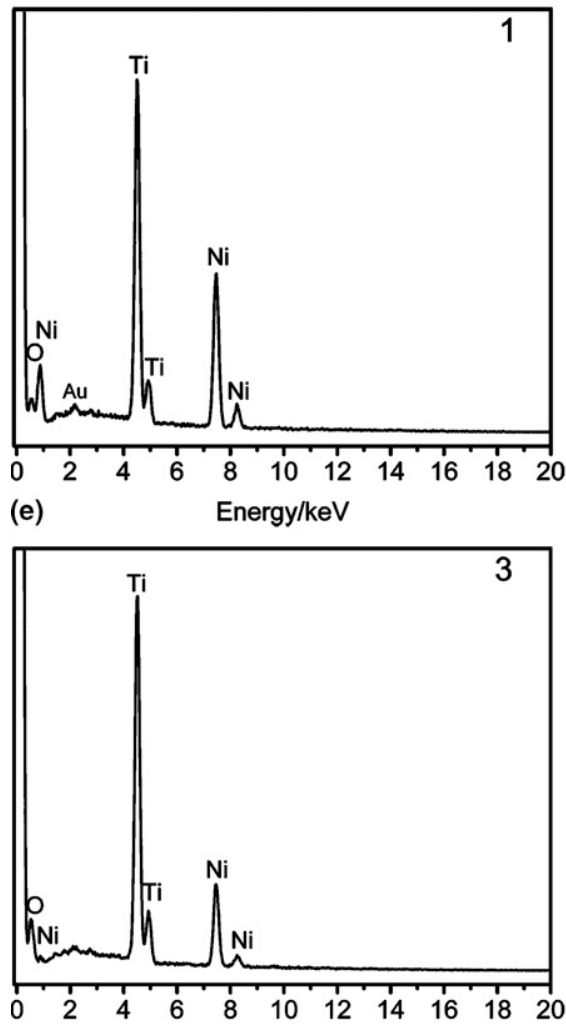

(g)

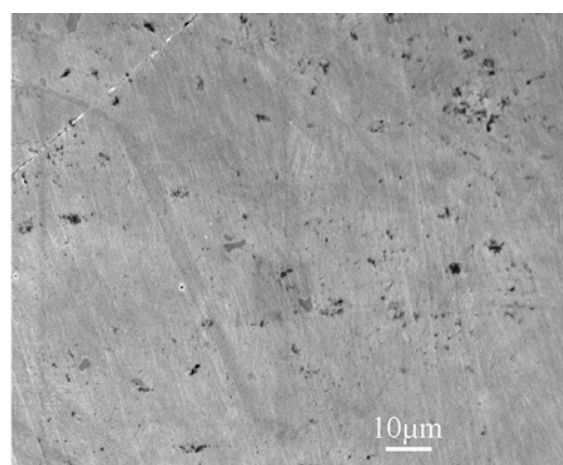

(b)

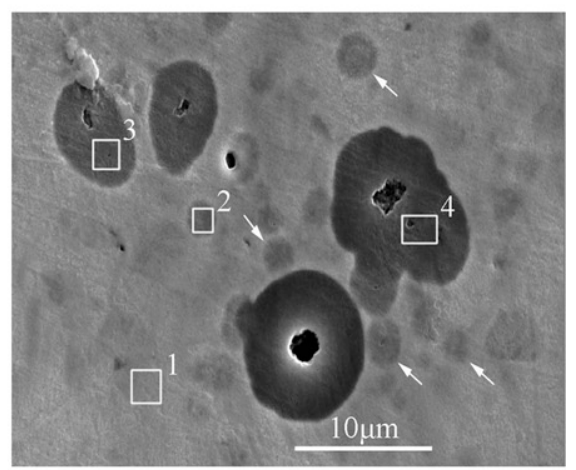

(d)
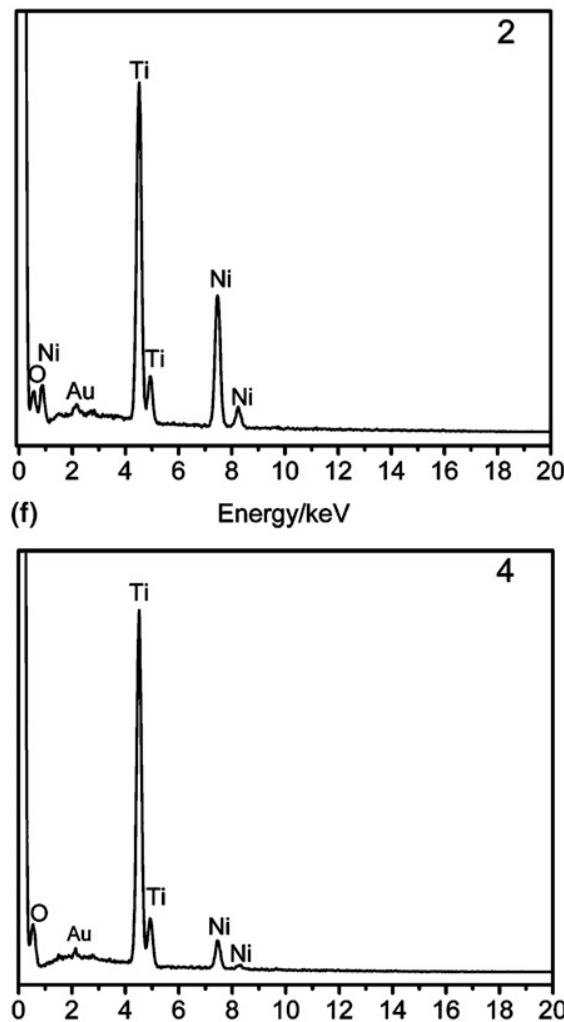

(h)

FIG. 1. Surface morphology of NiTi specimens after immersion in the $0.9 \% \mathrm{NaCl}$ physiological solution after: (a) 2 weeks, (b) 5 weeks, and (c) 8 weeks; (d) high magnification of (c); (e)-(h) EDS spectra acquired from selected regions 1-4 in (d). 
were analyzed by EDS after immersion for 8 weeks, and the results are displayed in Figs. 1(e) to 1(h). It can be found that Region 1 with slight corrosion has a relatively high concentration of Ni. In comparison, surface corrosion becomes severe in Regions 2 to 4 with the surface concentration of Ni decreasing significantly and those of $\mathrm{O}$ and Ti increasing gradually. The detailed elemental concentrations are listed in Table I. The low Ni concentration on the corroded surface suggests that pitting corrosion results in nickel release from the bulk materials to the $\mathrm{NaCl}$ solu-

TABLE I. Elemental composition of NiTi specimen immersed in the $0.9 \% \mathrm{NaCl}$ physiological solution for 8 weeks.

\begin{tabular}{llcr}
\hline \hline & \multicolumn{3}{c}{ Element composition (at.\%) } \\
\cline { 2 - 4 } Region & \multicolumn{1}{c}{$\mathrm{O}$} & $\mathrm{Ti}$ & $\mathrm{Ni}$ \\
\hline $\mathrm{d} 1$ & 62.33 & 15.69 & 21.98 \\
d2 & 62.2 & 20.80 & 16.48 \\
d3 & 69.19 & 21.09 & 9.61 \\
d4 & 74.06 & 22.18 & 3.62 \\
\hline \hline
\end{tabular}

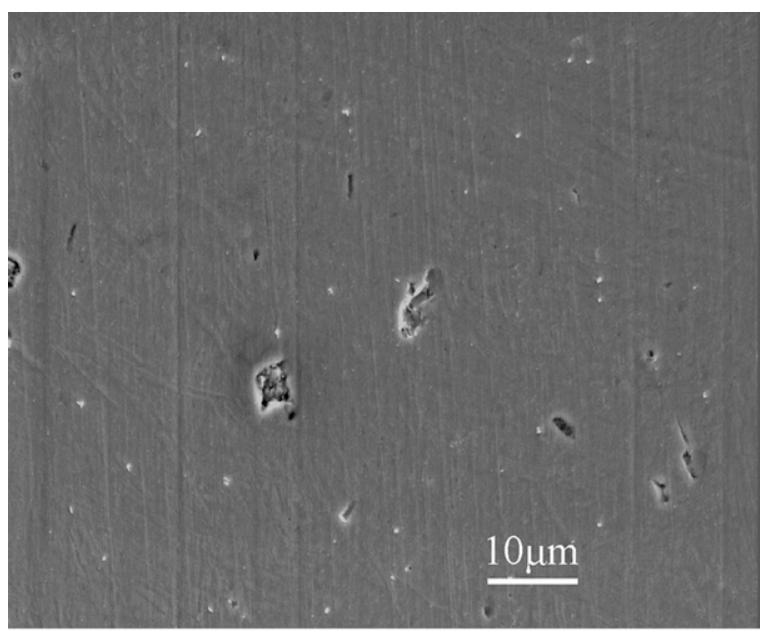

(a)

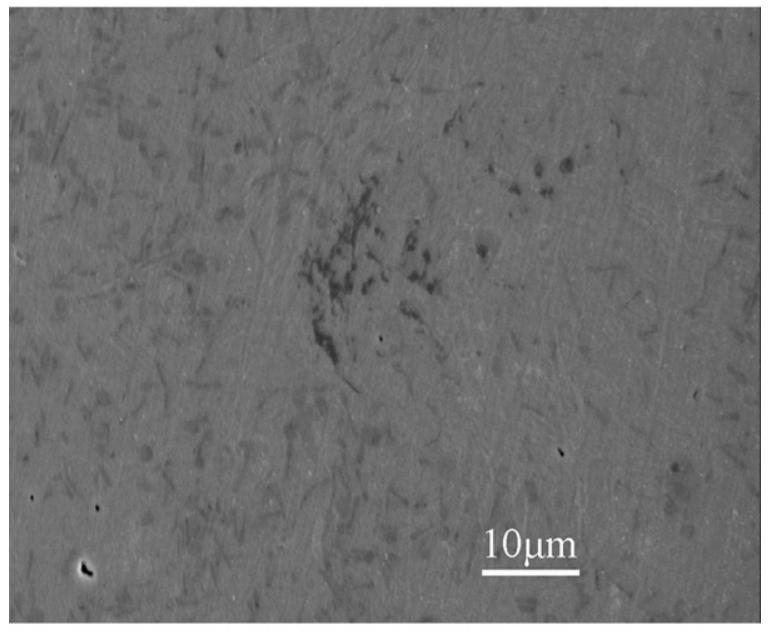

(b)

FIG. 2. Surface morphology of the NiTi specimens after immersion in $0.9 \% \mathrm{NaCl}$ physiological solution for (a) 12 weeks and (b) 30 weeks. tion. Meanwhile, the remaining Ti reacts with dissolved oxygen in solution to form titanium oxides in the corroded area. The atomic ratio of $\mathrm{O}$ to $\mathrm{Ti}$ is greater than 2 attributable to chemical absorption of $-\mathrm{CO}$ on the surface. Our results demonstrate that nickel release and titanium oxide formation occur simultaneously during pitting corrosion on NiTi SMAs in the $\mathrm{NaCl}$ solution. As a result, the corrosion product consists of a layer of titanium oxides.

Figures 2(a) and 2(b) show the typical surface morphologies after immersion in the $0.9 \% \mathrm{NaCl}$ solution for 12 and 30 weeks, respectively. In Fig. 2(a), only pitting
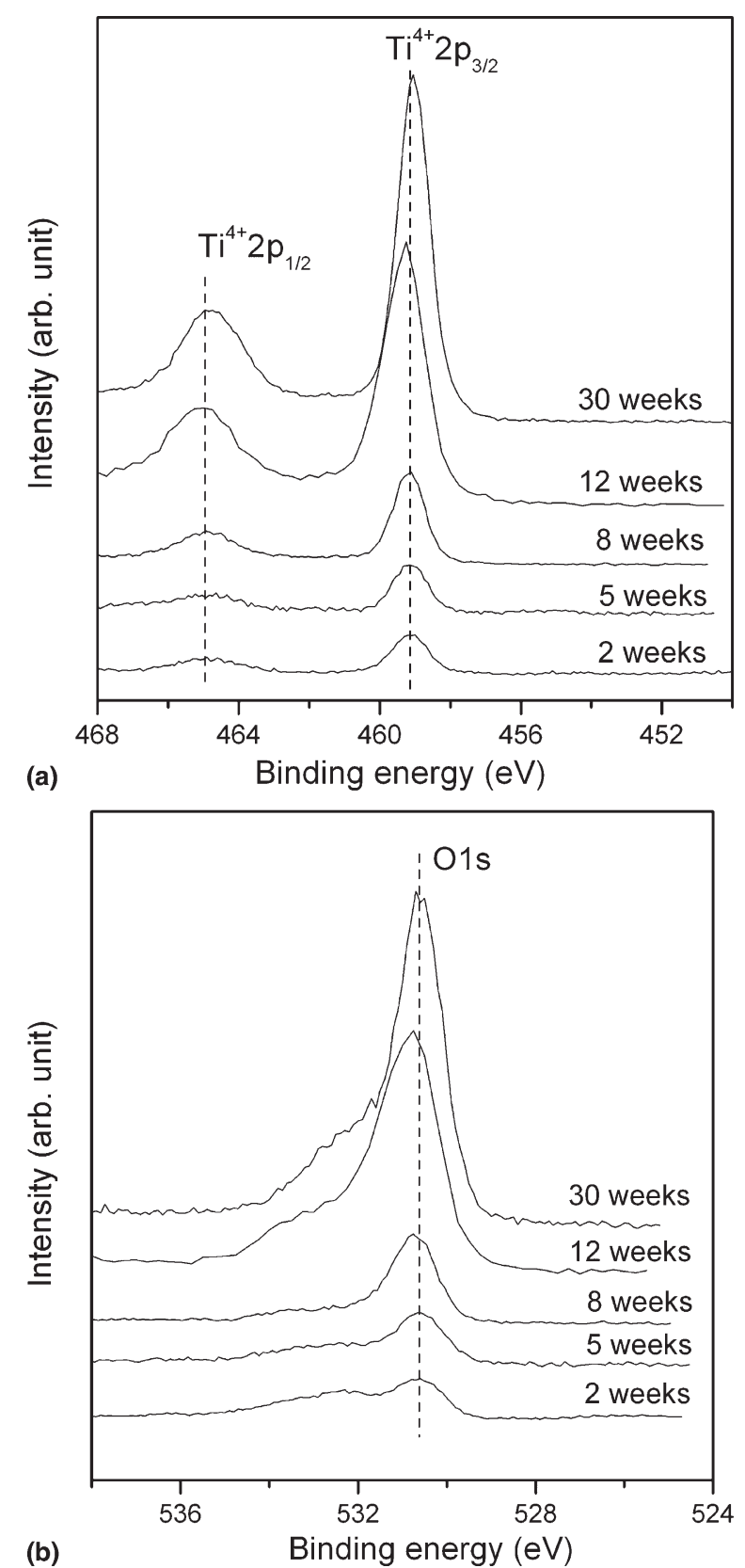

FIG. 3. Ti $2 p$ and O 1s XPS spectra acquired from the surface of the NiTi specimens after immersion in the $0.9 \% \mathrm{NaCl}$ physiological solution for $2,5,8,12$, and 30 weeks. 
pores can be found on the surface while the dark area around the pitting pores disappear after 12 weeks of immersion. Figure 2(b) shows a different surface morphology after immersion for 30 weeks. The entire surface is covered by a uniform and dense film instead of many pitting holes, although some tiny pores still exist on the surface. Undoubtedly, this film resulting from prolonged corrosion by aggressive $\mathrm{Cl}^{-}$is mainly composed of titanium oxides. Our results show proof that the corrosion-induced titanium oxide layer grows and cures the pitting pores on the NiTi surface if the immersion time is long enough.

To obtain more detailed information on the constituents of the corrosion-induced titanium oxide layer on the NiTi specimens, XPS is used to examine the elemental chemical states. Figures 3(a) and 3(b) display the surface $\mathrm{Ti} 2 \mathrm{p}$ and $\mathrm{O} 1 \mathrm{~s}$ spectra of the NiTi specimens after different immersion time. As shown in Fig. 3(a), the Ti $2 p$ spectrum exhibits two main peaks with binding energies of about $465.0 \mathrm{eV}\left(\mathrm{Ti}^{4+} 2 \mathrm{p}_{1 / 2}\right)$ and $459.2 \mathrm{eV}\left(\mathrm{Ti}^{4+}\right.$ $2 p_{3 / 2}$ ), indicating that titanium on the surface is mainly in the form of titanium oxide. ${ }^{23}$ The intensity of both the
$465.0 \mathrm{eV}\left(\mathrm{Ti}^{4+} 2 \mathrm{p}_{1 / 2}\right)$ and $459.2 \mathrm{eV}\left(\mathrm{Ti}^{4+} 2 \mathrm{p}_{3 / 2}\right)$ peaks increases with immersion time in the $0.9 \% \mathrm{NaCl}$ solution. The $\mathrm{O}$ 1s spectra are shown in Fig. 3(b). The main peak has a binding energy of $530.8 \mathrm{eV}$, which can be assigned to oxygen present in metal oxides, ${ }^{22}$ and the peak intensity increases with immersion time. This indicates that titanium oxide becomes the dominant corrosion product on the surface of the NiTi specimens as the immersion time increases. The peak broadening observed from the $\mathrm{O} 1 \mathrm{~s}$ peak after immersion for 12 weeks may be attributed to absorption of $-\mathrm{OH}$ and $-\mathrm{CO}$ groups on the surface. ${ }^{8}$

Figure 4 shows the XPS depth profiles of the corroded NiTi specimens compared with the mechanically polished one. The thickness of the corrosion-induced titanium oxide layer can be estimated from the depth profiles at which the oxygen signal drops to one-half of its surface value. ${ }^{24}$ Taking a sputtering rate of $7.8 \mathrm{~nm} / \mathrm{min}$, the thickness of the native oxide film on the mechanically polished samples is about $4 \mathrm{~nm}$, which is within the range reported for NiTi in the literature. ${ }^{1,14,25}$ On the other hand, the thicknesses of the titanium oxide films on the NiTi specimens after immersion for 12 and 30 weeks are about 31
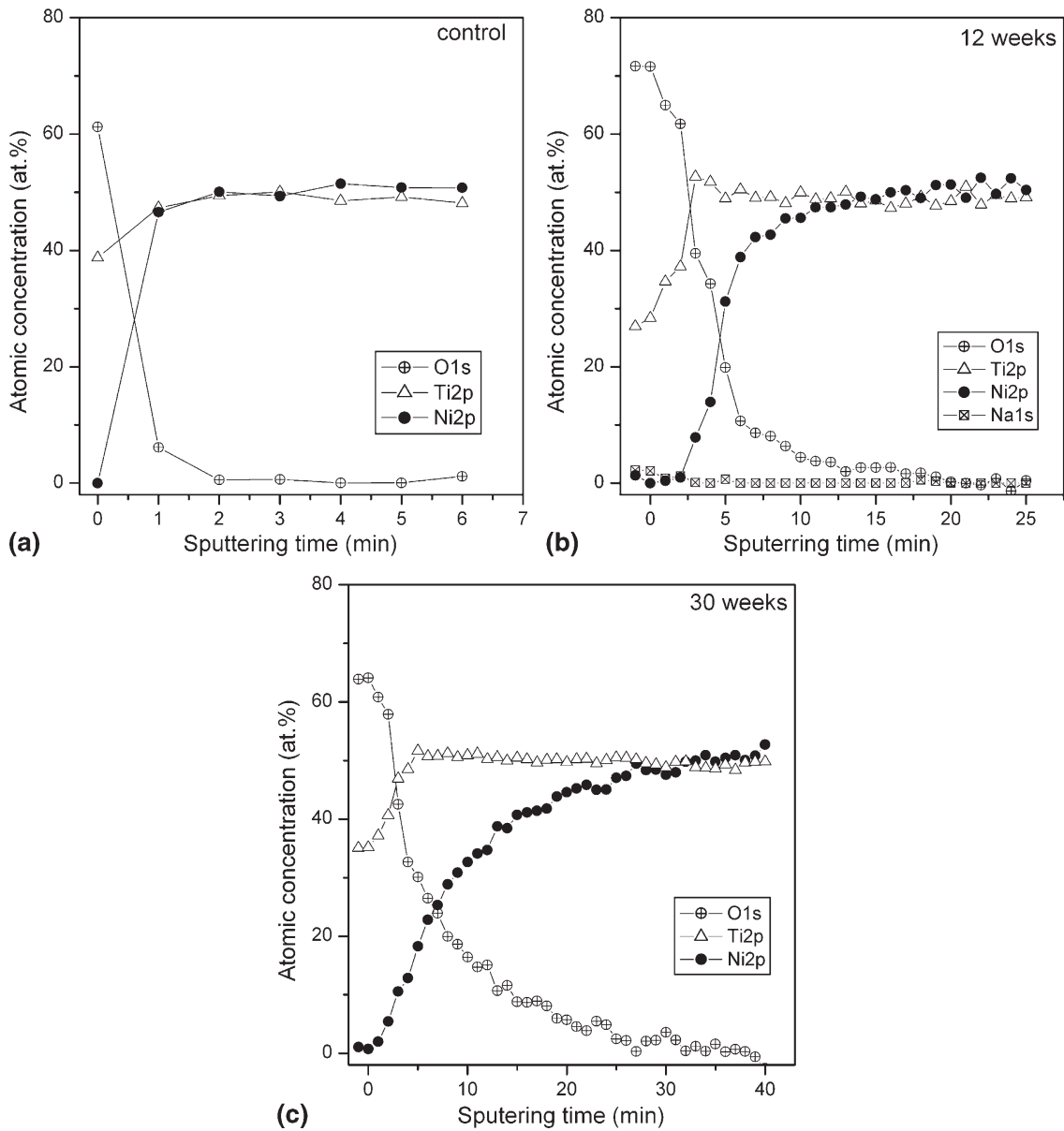

FIG. 4. XPS depth profiles obtained from the surface of the NiTi SMAs. (a) Mechanically polished NiTi without immersion and NiTi specimens immersed in the $0.9 \% \mathrm{NaCl}$ physiological solution for (b) 12 weeks and (c) 30 weeks. 
and $40 \mathrm{~nm}$, respectively. It should be noted that the thickness of the corrosion product layer does not increase linearly with time. The growth rate decreases as corrosion proceeds, indicating that the as-formed titanium oxide layer may impede further corrosion of the NiTi SMAs in the $\mathrm{NaCl}$ solution.

High-resolution XPS measurements of both the Ti and $\mathrm{Ni}$ binding energy as a function of the sputtering time were conducted on the NiTi SMAs after immersion for 30 weeks. The Ti $2 p$ spectra are corrected for background and scattering using the Shirley method. ${ }^{26}$ Deconvolution of the $\mathrm{Ti} 2 \mathrm{p}$ spectra is accomplished using four oxidation states, $\mathrm{Ti}^{4+}, \mathrm{Ti}^{3+}, \mathrm{Ti}^{2+}$, and $\mathrm{Ti}^{0}$, with corresponding $2 \mathrm{p}_{3 / 2}$ peaks at $459.2,457.5,455.3$, and $454.5 \mathrm{eV}$, and $2 \mathrm{p}_{1 / 2}$ peaks at 465.0, 463.5, 461.5, and $460.6 \mathrm{eV} .^{23}$ It can be observed from Fig. 5(a) that Ti at the outmost surface (curve 1) is essentially composed of $\mathrm{Ti}^{4+}, \mathrm{Ti}^{3+}$, and $\mathrm{Ti}^{2+}$ corresponding to $\mathrm{TiO}_{2}, \mathrm{Ti}_{2} \mathrm{O}_{3}$, and TiO. There is no $\mathrm{Ti}^{0}$ as the intermetallic NiTi state, indicating that the outermost surface layer is mainly composed of titanium oxides. Deeper into the NiTi substrate, two peaks $\mathrm{Ti}^{0} 2 \mathrm{p}_{3 / 2}$ and $2 \mathrm{p}_{1 / 2}$ corresponding to intermetallic NiTi state emerge and change gradually into the dominant peaks. After sputtering for $30 \mathrm{~min}$, the main chemical state of $\mathrm{Ti}$ is intermetallic NiTi. It is noted that there is no $\mathrm{NiO}$ observed on the corroded surface according to our XPS results in spite of the fact that NiTi contains a large amount of Ni. This is caused by the difference in the oxygen affinity between $\mathrm{Ti}$ and $\mathrm{Ni}$. The heats of formation of $\mathrm{TiO}_{2}$ and $\mathrm{NiO}$ are approxi-

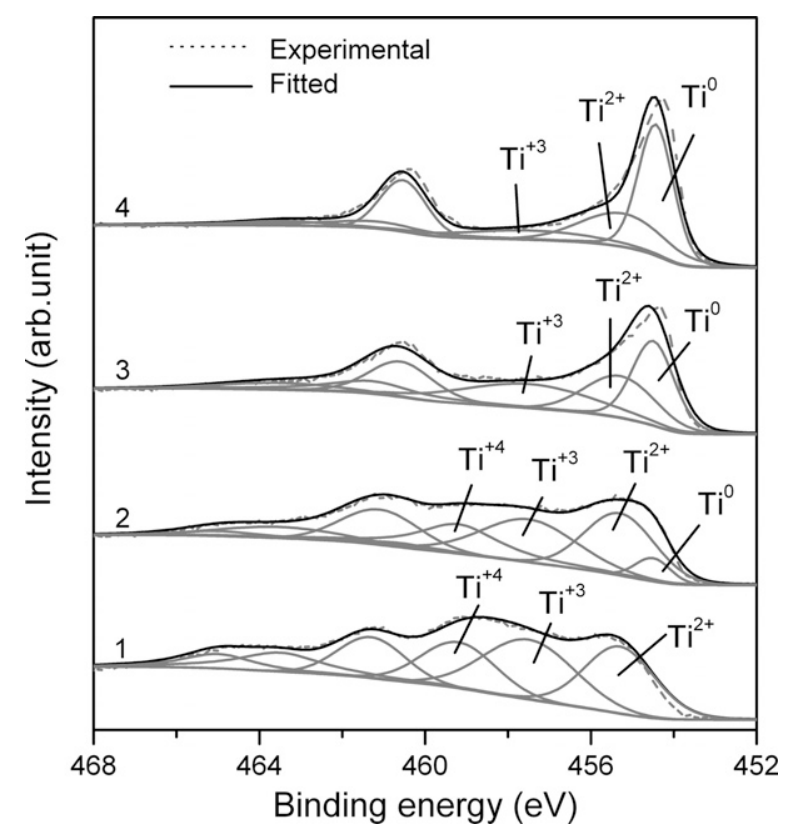

FIG. 5. High-resolution Ti $2 p$ XPS spectra acquired from the surface of NiTi specimens immersed in the $0.9 \% \mathrm{NaCl}$ physiological solution for 30 weeks at different sputtering times: (1) $0 \mathrm{~min}$, (2) $5 \mathrm{~min}$, (3) $10 \mathrm{~min}$, and (4) $30 \mathrm{~min}$. mately -956 and $-241 \mathrm{~kJ} / \mathrm{mol}$, respectively, ${ }^{27}$ implying that means $\mathrm{Ti}$ is easily oxidized whereas $\mathrm{Ni}$ is more difficult to oxidize. The titanium oxide layer is composed of transient $\mathrm{Ti}$ oxides, $\mathrm{TiO}$, and $\mathrm{Ti}_{2} \mathrm{O}_{3}$, because of insufficient oxidation at low temperature. The Ti-oxygen bond is more stable, and the resulting oxides do not easily dissolve into the solution after corrosion, which has been observed from $\mathrm{H}_{2} \mathrm{O}_{2}$ oxidized NiTi alloy. ${ }^{28}$

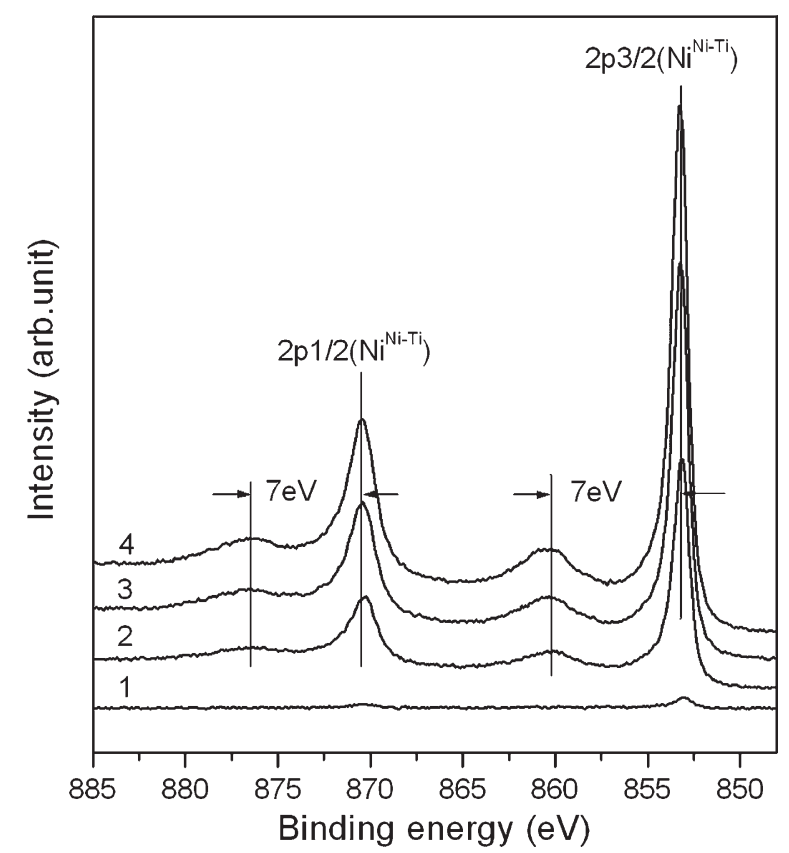

FIG. 6. Ni $2 p$ XPS spectra obtained from the surface of the NiTi specimens immersed in the $0.9 \% \mathrm{NaCl}$ physiological solution for 30 weeks at different sputtering times: (1) $0 \mathrm{~min}$, (2) $5 \mathrm{~min}$, (3) $10 \mathrm{~min}$, and (4) $30 \mathrm{~min}$.



FIG. 7. Concentration of nickel ions released from NiTi specimens to the $\mathrm{NaCl}$ solution as a function of immersion time. 
Figure 6 shows the high-resolution XPS collections of Ni $2 p$ spectra. Nearly no Ni peaks can be observed from the outermost surface layer (curve 1), implying that $\mathrm{Ni}$ ions are lost to the solution during the corrosion process giving rise to a nickel-free surface on the corroded NiTi specimen. At a greater depth, the Ni $2 \mathrm{p}$ spectra consist of two major peaks near 853.8 and $870.5 \mathrm{eV}$, which correspond to $\mathrm{Ni}^{0} 2 \mathrm{p}_{3 / 2}$ and $2 \mathrm{p}_{1 / 2}$ in the intermetallic NiTi state. Two small peaks separated from the main peaks by $\sim 7 \mathrm{eV}$ are attributed to the satellite structure of the main peaks. ${ }^{29}$ The changes in the $\mathrm{Ni} 2 \mathrm{p}$ spectra are consistent with those observed from the Ti $2 p$ spectra.

TABLE II. Concentration (ppb) of nickel leached from NiTi specimens immersed in the $0.9 \% \mathrm{NaCl}$ physiological solution for $2,5,8$, 12 , and 30 weeks, respectively.

\begin{tabular}{lccccc}
\hline \hline & \multicolumn{5}{c}{ Immersion time (weeks) } \\
\cline { 2 - 6 } & 2 & 5 & 8 & 12 & 30 \\
\hline Nickel ion & 11.7 & 18.3 & 48.0 & 65.3 & 133.3 \\
$\quad$ concentration & \pm 1.3 & \pm 0.7 & \pm 2.0 & \pm 2.2 & \pm 1.7 \\
$(\mathrm{ppb})$ & & & & & \\
\hline \hline
\end{tabular}

To assess the release of nickel ions from the NiTi specimens into the $\mathrm{NaCl}$ solution, ICPAES was adopted. Figure 7 shows the amounts of Ni released from NiTi specimens to the $\mathrm{NaCl}$ solution as a function of immersion time, and Table II gives the Ni concentrations. The amounts of $\mathrm{Ni}$ ions increase with immersion time. It can be observed that the slope increases after immersing for 5 weeks and then decreases after 8 weeks. Since the slope of the curve in Fig. 7 is equal to the Ni release rate, it is clear that the nickel release rate varies with immersion time and is higher between 5 and 8 weeks. It can thus be inferred that the change in the release rate is related to the corrosion defects such as pitting pores on the NiTi specimens. In the early immersion period, nickel ions are released gradually into the surrounding solution. As the immersion continues, corrosion results in the formation of pitting pores that promote nickel release, leading to a high nickel release rate. However, if the immersion time is long enough, the corrosion-induced titanium oxide layer seals the pitting pores on the NiTi surface, thereby reducing the Ni release rate.

According to the aforementioned experimental results, a mechanism is proposed and the schematic diagram is

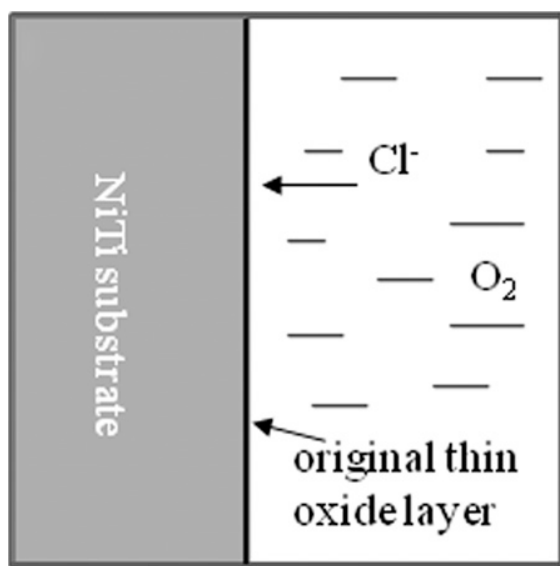

(a)

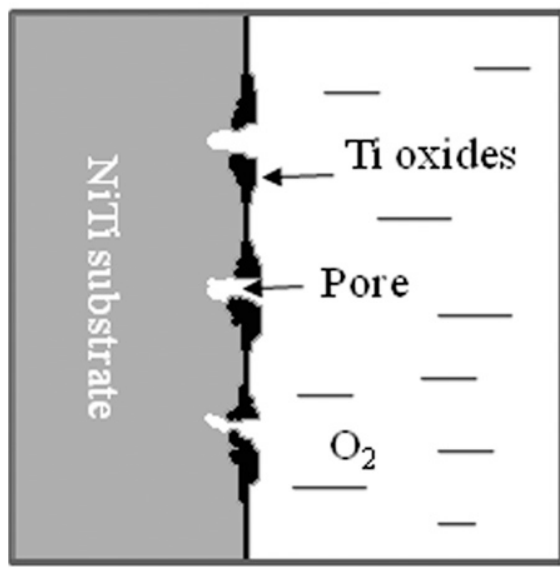

(c)

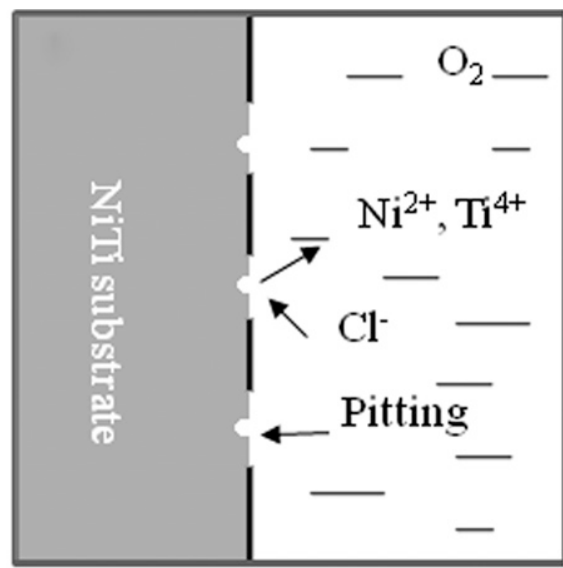

(b)

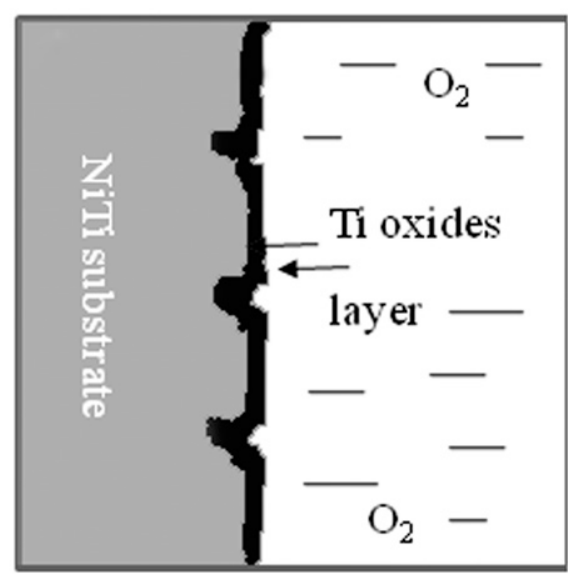

(d)

FIG. 8. Corrosion product layer formation on NiTi SMAs in the $\mathrm{NaCl}$ solution. 
illustrated in Fig. 8. Upon exposure to the $\mathrm{NaCl}$ solution, the original thin oxide layer on the NiTi specimens are vulnerable to attack by $\mathrm{Cl}^{-}$as shown in Fig. 8(a). As shown in the SEM image in Fig. 1(a), early pitting corrosion takes place on many sites on the surface. This process is illustrated in Fig. 8(b). Early corrosion process takes place on surface defects initially and involves the breakdown of original thin oxide layer and $\mathrm{Ni}-\mathrm{Ti}$ bond after attack by $\mathrm{Cl}^{-}$. This process releases nickel ions. As time elapses, the pitting sites propagate and noticeable pores form on the surface as confirmed by the SEM result in Fig. 1. Nickel released from the bulk materials into the solution reduces the local concentration of nickel in the materials. Meanwhile, the remaining titanium reacts with dissolved oxygen in the solution to form titanium oxides around the pitting sites and pores, as shown in Fig. 8(c). As the corrosion process proceeds, the titanium oxide layer grows and propagates over the entire surface of the NiTi specimen, as shown in Fig. 2(b). Moreover, the pores formed during corrosion are possibly blocked by the titanium oxides formed inside the pores. As a result, a uniform and dense oxide layer is formed on the NiTi SMAs, as shown in Fig. 8(d).

After the titanium oxide layer has formed on the entire surface of the NiTi specimen, it will serve as a passivation film to retard the corrosion process. Many studies have demonstrated that the titanium oxide film on the NiTi alloy serves as a barrier against outward diffusion of metal ions from the bulk alloy. Although titanium oxides possess good biocompatibility, the biological properties also depend on the quality of the titanium oxides film, e.g., surface defects, film bonding strength to the NiTi substrate, and so on. In this study, the corrosion product layer is found to consist of mainly titanium oxides formed during the corrosion process in the $0.9 \%$ $\mathrm{NaCl}$ physiological solution. These findings suggest that NiTi shape memory alloys can improve their own biocompatibility by the corrosion-induced titanium oxides formed on its surface during corrosion.

\section{CONCLUSION}

Mechanically polished NiTi alloy samples are subjected to corrosion in a $0.9 \% \mathrm{NaCl}$ physiological solution for 2, 5, 8, 12, and 30 weeks. The corrosion product layers on the NiTi specimens are characterized by SEM, EDS, and XPS. The following conclusions can be drawn:

(1) Pitting corrosion initiates on the surface of NiTi specimens in the $\mathrm{NaCl}$ solution. As the immersion time increases, pitting corrosion propagates onto the entire surface of the materials.

(2) During the corrosion process, nickel ions are released from the bulk materials into the solution. Meanwhile, the remaining titanium reacts with oxygen to form titanium oxides in the corrosion product layer.
(3) The corrosion product layer is composed of $\mathrm{TiO}_{2}$ as well as other sub $\mathrm{Ti}$ oxides, $\mathrm{TiO}$, and $\mathrm{Ti}_{2} \mathrm{O}_{3}$ and is relatively depleted of $\mathrm{Ni}$.

(4) The growth rate of the titanium oxide film decreases with corrosion time, and the film impedes further corrosion.

\section{ACKNOWLEDGMENTS}

The authors are grateful to Dr. Chenglong Liu, associate professor from Chongqing University of Technology, for his useful suggestions. Financial support from Hong Kong Research Grants Council (RGC) General Research Fund (GRF) No. CityU 112307 is acknowledged.

\section{REFERENCES}

1. S.A. Shabalovskaya: Surface, corrosion and biocompatibility aspects of nitinol as an implant material. Bio-Med. Mater. Eng. 12, 69 (2002).

2. K.W.K. Yeung, W.W. Lu, K.D.K. Luk, and K.M.C. Cheung: Mechanical testing of a smart spinal implant locking mechanism based on nickel-titanium alloy. Spine 31, 2296 (2006)

3. T. Duerig, A. Pelton, and D. Stockel: An overview of nitinol medical applications. Mater. Sci. Eng., A 273-275, 149 (1999).

4. F. Widu, D. Drescher, R. Junker, and C. Bourauel: Corrosion and biocompatibility of orthodontic wires. J. Mater. Sci.- Mater. Med. 10, 275 (1999)

5. F.X. Gil, J.M. Manero, and J.A. Planell: Relevant aspects in the clinical applications of NiTi shape memory alloys. J. Mater. Sci. Mater. Med. 7, 403 (1996).

6. S.A. Shabalovskaya: On the nature of the biocompatibility and on medical applications of NiTi shape memory and superelastic alloys. Bio-Med. Mater. Eng. 6, 267 (1996).

7. S.W. Robertson and R.O. Ritchie: In vitro fatigue-crack growth and fracture toughness behavior of thin-walled superelastic nitinol tube for endovascular stents: A basis for defining the effect of crack-like defects. Biomaterials 28, 700 (2007).

8. S.A. Shabalovskaya, H. Tian, J.W. Anderegg, D.U. Schryvers, W.U. Carroll, and J.V. Humbeeck: The influence of surface oxides on the distribution and release of nickel from Nitinol wires. Biomaterials 30, 468 (2009).

9. N. Shevchenko, M.T. Pham, and M.F. Maitz: Studies of surface modified NiTi alloy. Appl. Surf. Sci. 235, 126 (2004).

10. W. Jia, M.W. Beatty, R.A. Reinhardt, T.M. Petro, D.M. Cohen, C.R. Maze, E.A. Strom, and M. Hoffman: Nickel release from orthodontic arch wires and cellular immune response to various nickel concentrations. J. Biomed. Mater. Res. Part B 48, 488 (1999).

11. W.M. Carroll and M.J. Kelly: Corrosion behavior of nitinol wires in body fluid environments. J. Biomed. Mater. Res. A 67, 1123 (2003).

12. G. Rondelli: Corrosion resistance tests on NiTi shape memory alloy. Biomaterials 17, 2003 (1996).

13. J.Q. Wang, N.X. Li, E.H. Han, and W. Ke: Effect of pH, temperature and $\mathrm{Cl}^{-}$concentration on electrochemical behavior of NiTi shape memory alloy in artificial saliva. J.Mater. Sci. Mater. Med. 17, 885 (2006).

14. D.J. Wever, A.G. Veldhuizen, J. de Vries, H.J. Busscher, D.R.A. Uges, and J.R. van Horn: Electrochemical and surface characterization of a nickel-titanium alloy. Biomaterials 19,761 (1998).

15. G. Rondelli, P. Torricelli, M. Fini, L. Rimondini, and R. Giardino: In vitro corrosion study by EIS of an equiatomic NiTi alloy and an implant quality AISI 316 stainless steel. J. Biomed. Mater. Res. B 79, 320 (2006). 
16. X.J. Li, J.Q. Wang, E.H. Han, and W. Ke: Influence of fluoride and chloride on corrosion behavior of $\mathrm{NiTi}$ orthodontic wires. Acta Biomater. 3, 807 (2007).

17. B. Clarke, W. Carroll, Y. Rochev, M. Hynes, D. Bradley, and D. Plumley: Influence of nitinol wire surface treatment on oxide thickness and composition and its subsequent effect on corrosion resistance and nickel ion release. J. Biomed. Mater. Res. Part A 76, 61 (2006).

18. H.H. Huang, Y.H. Chiu, T.H. Lee, S.C. Wu, H.W. Yang, K.H. Su, and C.C. Hsu: Ion release from NiTi orthodontic wires in artificial saliva with various acidities. Biomaterials 24, 3585 (2003).

19. G. Rondelli and B. Vicentini: Localized corrosion behavior in simulated human body fluids of commercial $\mathrm{Ni}-\mathrm{Ti}$ orthodontic wires. Biomaterials 20.785 (1999).

20. Y.C. Xin, K.F. Huo, T. Hu, G.Y. Tang, and K. Paul Chu: Corrosion products on biomedical magnesium alloy soaked in simulated body fluids. J. Mater. Res. 24, 2711 (2009).

21. M. Pourbaix: Electrochemical corrosion of metallic biomaterials. Biomaterials 5, 122 (1984).

22. S.A. Shabalovskaya and J.W. Anderegg: Surface spectroscopic characterization of TiNi nearly equiatomic shape memory alloys for implants. J.Vac. Sci. Technol., A 13, 2624 (1995).
23. M.H. Wong, F.T. Cheng, G.K.H. Pang, and H.C. Man: Characterization of oxide film formed on NiTi by laser oxidation. Mater. Sci. Eng., A 448, 97 (2007).

24. C.L. Chu, T. Hu, S.L. Wu, Y.S. Dong, L.H. Yin, Y.P. Pu, P.H. Lin, C.Y. Chung, K.W.K. Yeung, and K. Paul Chu: Surface structure and properties of biomedical NiTi shape memory alloy after Fenton's oxidation. Acta Biomater. 3, 795 (2007).

25. M.H. Wong, F.T. Cheng, and H.C. Man: In situ hydrothermal synthesis of oxide film on NiTi for improving corrosion resistance in Hank's solution. Scr. Mater. 56, 205 (2007).

26. M.P. Seah: Quantification of AES and XPS, in Practical Surface Analysis, Auger and X-ray Photoelectron Spectroscopy, Vol. 1, 2nd ed., edited by D. Briggs and M.P. Seah (John Wiley and Sons, Chichester, UK, 1990).

27. R.C. Weast and M.J. Astle: CRC Handbook of Chemistry and Physics (CRC Press, Boca Raton, FL, 1982).

28. C.L. Chu, C.Y. Chung, and P.K. Chu: Surface oxidation of NiTi shape memory alloy in a boiling aqueous solution containing hydrogen peroxide. Mater. Sci. Eng.. A 417, 104 (2006).

29. C.L. Chu, C.Y. Chung, Y.P. Pu, and P.H. Lin: Graded surface structure in chemically polished NiTi shape memory alloy after $\mathrm{NaOH}$ treatment. Scr. Mater. 52, 1117 (2005). 